\title{
Plasma Atherogenic Index in Type 2 Diabetes Mellitus Patients
}

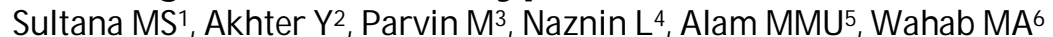

DOI: https:/ / doi.org/ 10.3329/ jafmc.v15i2.50837

\section{Abstract}

Introduction: Atherogenic index of plasma (AIP) is defined as log of TG to HDL-C ratio. People with high AIP have a higher risk for coronary heart disease (CHD) than those with low AIP. AIP is useful in predicting atherogenecity.

Objectives: To determination of AIP among the study subjects and find out the prevalence of AIP among type 2 diabetes mellitus (DM) patients.

Materials and Methods: This cross sectional study was conducted at Armed Forces Institute of Pathology (AFIP) from November 2014 to October 2015. The study included 300 type 2 DM patients belonging to the age group 30-60 years. Fasting plasma glucose (FPG), HDL-C, TG were estimated. The AIP was calculated as $\log$ (TG/HDL-C) using the Czech online calculator of atherogenic risk. Personal data and history of co-existing medical conditions were collected by data collection sheet. Data were analyzed by SPSS version 18.0.

Results: Among 300 study subjects the AIP were found in the range of "increased risk" in 298(99.3\%) and "low risk" in 02(0.7\%). In this study mean FPG was $9.81 \pm 3.08 \mathrm{mmol} / \mathrm{L}$ and mean AIP was $0.73 \pm$ $0.23 \mathrm{~A}$ and significant positive correlation between FPG and AIP ( $r=$ $0.123, p<0.05$ ) was observed.

Conclusion: The study revealed that AIP is significantly higher in type 2 DM patients. So, patients with type 2 DM should be followed up with AIP regularly.

Key-words: Type 2 Diabetes mellitus, Atherogenic Index of Plasma (AIP), Atherosclerosis.

\section{Introduction}

Diabetes mellitus (DM) is a clinical syndrome characterized by hyperglycemia due to absolute or relative deficiency of insulin1. Atherogenic index of plasma (AIP) is defined as log of TG to HDL-C ratio. People with high AIP have a higher risk for coronary heart disease (CHD) than those with low AIP. AIP is useful in predicting atherogenecity 2,3. Triglycerides and HDL-cholesterol in AIP reflect the balance between the atherogenic and antiatherogenic lipoproteins respectively4. Prolonged hyperglycaemia and insulin resistance increase lipogenesis and increase TG concentrations and decreases HDL-C and thus may contribute for elevation of AIP in DM patients. AIP is an easily available CHD risk marker and a useful measure of response to treatment 5 .

\section{Materials and Methods}

This descriptive cross-sectional study conducted in the department of Biochemistry, Armed Forces Institute of Pathology (AFIP), Dhaka from November 2014 to October 2015. A total of 300 type 2 DM patients were included in the study based on non probability sampling method belonging to the age group 30-60 years which included 50\% men and 50\% women. Individuals who have FPG $\geq 7$ $\mathrm{mmol} / \mathrm{L}$ were included in this study. Individuals known to have liver disease, kidney disease, malignant disease, hypothyroidism, pregnancy and patient on lipid lowering drug were excluded from the study. AIP $<0.11$ considered as low risk; 0.11 to 0.21 as intermediate risk and $>0.21$ as increased risk. After selection of study subjects, informed written consent was taken, then relevant history was taken and fasting plasma glucose, serum TG and HDL-C was measured. AIP was calculated from TG/HDL-C by online calculator and expressed as percentage. Collected data were analyzed by SPSS version 18.0. Categorical data were expressed as frequency and percentage and continuous data as mean \pm SD. Relevant statistical analysis was done and $p$ value $<0.05$ was considered as significance.

\section{Results}

In this study, age range of 300 patients was 30-60 years; 44(14.7\%) patients were in age group 30-39 years, 132(44\%) were in age group 40-49 years, 124(41.3\%) were in age group 50-59 years. There was no significant difference $(p>0.05)$ among the groups in respect of sex (Table-I). In this study mean FPG was $9.81 \pm 3.08 \mathrm{mmol} / \mathrm{L}$ and mean AIP was $0.73 \pm 0.23$. There was no significant difference of mean FPG and AIP ( $p>0.05)$ between male and female (Table-II). In our study 298 type 2 diabetic patients (99.3\%) had increased risk AIP and 02 patients (0.7\%) had low risk AIP. There was no significant difference of pattern of distribution of AIP ( $p>0.05)$ between male and female (Table-III) and different age group (Table-IV). Among the diabetic subjects Pearson's correlation analysis showed positive correlation between fasting plasma glucose and AIP ( $r=0.123, p=0.033)$. The finding was found statistically significant (Figure-1).

Table-I: Distribution of patients by age group and sex

\begin{tabular}{|c|c|c|c|c|c|}
\hline \multicolumn{2}{|c|}{ Characteristics } & $\begin{array}{c}\text { Male } \\
\mathrm{n}(\%)\end{array}$ & $\begin{array}{c}\text { Female } \\
\mathrm{n}(\%)\end{array}$ & $\begin{array}{c}\text { Total } \\
\mathrm{n}(\%)\end{array}$ & $\begin{array}{c}\text { p } \\
\text { value }\end{array}$ \\
\hline \multirow{7}{*}{$\begin{array}{c}\text { Age in } \\
\text { years }\end{array}$} & $30-39$ & $\begin{array}{c}24 \\
(16.0)\end{array}$ & $\begin{array}{c}20 \\
(13.3)\end{array}$ & $\begin{array}{c}44 \\
(14.7)\end{array}$ & \\
\cline { 2 - 5 } & $40-49$ & $\begin{array}{c}66 \\
(44.0)\end{array}$ & $\begin{array}{c}66 \\
(44.0)\end{array}$ & $\begin{array}{c}132 \\
(44.0)\end{array}$ & $\begin{array}{c}\mathrm{X}^{2}=0.493 \\
\mathrm{df}=2 \\
\mathrm{p}>0.05\end{array}$ \\
\cline { 2 - 5 } & $50-59$ & $\begin{array}{c}60 \\
(40.0)\end{array}$ & $\begin{array}{c}64 \\
(42.7)\end{array}$ & $\begin{array}{c}124 \\
(41.3)\end{array}$ & \\
\cline { 2 - 5 } & Total & $\begin{array}{c}150 \\
(100)\end{array}$ & $\begin{array}{c}150 \\
(100)\end{array}$ & $\begin{array}{c}300 \\
(100.0)\end{array}$ & \\
\hline
\end{tabular}

1. Lt Col Most. Sarmin Sultana, MBBS, MCPS, FCPS, Associate Professor of Biochemistry, Armed Forces Medical College (AFMC), Dhaka (E-mail: drsarmin101050@gmail.com) 2. Brig Gen Yasmin Akhter, MBBS, DCP, FCPS, Trainee Officer MMEd, Armed Forces Medical Institute, Dhaka. 3. Brig Gen Mimi Parvin, MBBS, MCPS, DCP, FCPS, Professor of Biochemistry, AFMC, Dhaka 4. Lt Col Lubna Naznin, MBBS, MCPS, DCP, FCPS, Classified specialist in Pathology, AFIP, Dhaka 5. Lt Col Md. Mahbub UI Alam, MBBS, DA, FCPS, Classified Specialist in Anaesthesiology, CMH, Dhaka 6. Lt Col Md Abdul Wahab, MBBS, MD, Associate Professor of Biochemistry, AFMC, Dhaka. 
Table-II: Distribution of patients according to FPG and AIP by sex

\begin{tabular}{|l|c|c|c|}
\hline FBG and AIP & Male & Female & p value \\
\hline FPG (mmol/L) & $10.04 \pm 3.35$ & $9.58 \pm 2.78$ & $p>0.05$ \\
\hline AIP & $0.76 \pm 0.21$ & $0.70 \pm 0.24$ & $p>0.05$ \\
\hline
\end{tabular}

Table-III: Pattern of distribution of AIP in male and female

\begin{tabular}{|c|c|c|c|c|}
\hline AIP & $\begin{array}{l}\text { Male } \\
\mathrm{n}(\%)\end{array}$ & $\begin{array}{c}\text { Female } \\
\mathrm{n}(\%)\end{array}$ & $\begin{array}{l}\text { Total } \\
\mathrm{n}(\%)\end{array}$ & $\begin{array}{c}p \\
\text { value }\end{array}$ \\
\hline Low risk $(<0.11)$ & $0(0.0)$ & $2(1.3)$ & $2(0.7)$ & \multirow{4}{*}{$p>0.05$} \\
\hline $\begin{array}{l}\text { Intermediate risk } \\
(0.11-0.20)\end{array}$ & $0(0.0)$ & $0(0.0)$ & $0(0.0)$ & \\
\hline $\begin{array}{l}\text { Increased Risk } \\
(>0.21)\end{array}$ & $150(100)$ & 148 (98.7) & $0(0.0)$ & \\
\hline Total & $150(100)$ & $150(100)$ & $298(99.3)$ & \\
\hline
\end{tabular}

Table-IV: Pattern of distribution of AIP in different age groups

\begin{tabular}{|c|c|c|c|c|c|}
\hline \multirow[b]{2}{*}{ AIP } & \multicolumn{4}{|c|}{ Age in years } & \multirow[b]{2}{*}{$\begin{array}{c}p \\
\text { value }\end{array}$} \\
\hline & $\begin{array}{c}30-39 \\
n(\%)\end{array}$ & $\begin{array}{c}40-49 \\
n(\%)\end{array}$ & $\begin{array}{c}50-59 \\
\mathrm{n}(\%)\end{array}$ & $\begin{array}{l}\text { Total } \\
\mathrm{n}(\%)\end{array}$ & \\
\hline $\begin{array}{l}\text { Low risk } \\
(<0.11)\end{array}$ & $0(0.0)$ & $2(1.5)$ & $0(0.0)$ & $2(0.7)$ & \multirow{4}{*}{$\begin{array}{c}p \\
>0.05\end{array}$} \\
\hline $\begin{array}{l}\text { Intermediate } \\
\text { risk (0.11-0.20) }\end{array}$ & $0(0.0)$ & $0(0.0)$ & $0(0.0)$ & $0(0.0)$ & \\
\hline $\begin{array}{l}\text { Increased } \\
\text { Risk }(>0.21)\end{array}$ & $44(100)$ & $130(98.5)$ & $124(100)$ & $298(99.3)$ & \\
\hline Total & $44(100.0)$ & $132(100)$ & $124(100)$ & $300(100)$ & \\
\hline
\end{tabular}

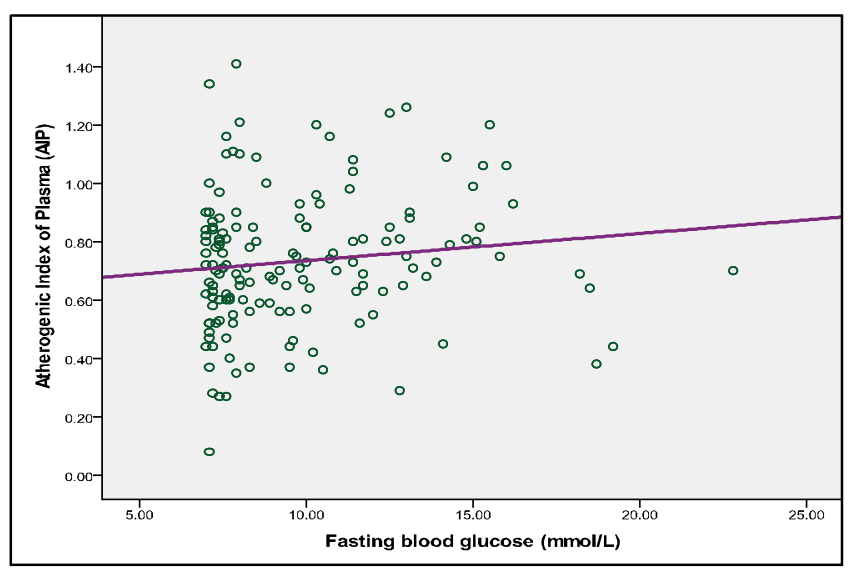

Figure-1: Correlation between FPG and AIP $(r=0.123 ; p<0.05)$.

\section{Discussion}

Several studies have indicated the role of AIP as early predictor of risk for development of atherosclerosis in DM patients ${ }^{6}$. In our study 298 type 2 diabetic patients (99.3\%) had increased risk AIP and 02 patients $(0.7 \%)$ had low risk AIP. Miric et al7 demonstrated that AIP was higher in patients with T2 DM. In DM prolonged hyperglycaemia and insulin resistance increase lipogenesis and increase TG concentrations and decreases HDL-C and thus may contribute for elevation of AIP in diabetic patients ${ }^{8}$. We observed a significant positive correlation between and fasting blood sugar and AIP $(r=0.123, p=0.033)$ in type $2 \mathrm{DM}$ patients. Sushith et al also observed that a significant positive correlation between and fasting blood sugar and AIP ( $r=0.434, p=0.01)$ in type 2 DM patients ${ }^{9}$. In DM prolonged hyperglycemia and insulin resistance increase the lipogenesis and increase TG concentrations and decrease the
HDL-C and thus may contribute to elevation of AIP levels in diabetic patient ${ }^{8,10}$. In our study, there was no significant difference $(p>0.05)$ in AIP level between male and female. AIP is a HDL-C based parameter, the female sex hormone estrogen tends to raise $\mathrm{HDL}$ cholesterol, and as a rule, women have higher HDL (good) cholesterol levels than men. Several studies have indicated the role of AIP as early predictor of risk for development of atherosclerosis in DM patients. In DM prolonged hyperglycaemia and insulin resistance increase lipogenesis and increase TG concentrations and decreases HDL-C and thus may contribute for elevation of AIP in diabetic patients, 5,6,11.

\section{Conclusion}

The study revealed that AIP is significantly higher in type 2 diabetic patients. AIP may be useful in predicting plasma atherogenicity. So, patients with type 2 DM should be followed up with AIP regularly.

\section{References}

1. Haq AU, Rahman JU, Mahmud $R$ et al. Pattern of lipid profile in type-2 diabetes mellitus patient. JPMI 2006; 20(4):366-9.

2. Okpa HO, Enang OE, Effa EE et al. Comparative analysis of atherogenic index of plasma and its relationship with cardiovascular risk among patients with diabetes mellitus and concurrent diabetes mellitus with hypertension attending endocrinology clinic in a tertiary hospital in South Nigeria. IOSR-JDMS 2015; 14 (4):102-107

3. George E. Differential effect of hormone therapy and tibolone on lipids, lipoproteins, and the atherogenic index of plasma christodoulakos. Journal of Cardiovascular Pharmacology 2006; 47(4):542-8.

4. Dobiásová $\mathrm{M}$ and Frohlich $\mathrm{J}$. The plasma parameter log (TG/HDL-C) as an atherogenic index: Correlation with lipoprotein particle size and esterification rate in apo B-lipoprotein-depleted plasma (FER (HDL). Clinical Biochemistry 2001; 34(7): 583-58.

5. D. Milada. Calculator of Atherogenic Risk. Available at: http:// www. biomed.cas.cz /fgu/ aip/ calculator. php. Accessed March 11, 20013.

6. Sushith, Shetty JK, Bhagavath $P$ et al. Comparison between lipid profile and atherogenic index of plasma (AIP) in alcoholic and nonalcoholic diabetes patients in Mangalone, South India. IJ AJIMS 2012; 1(1):10-4.

7. Miric DJ, Kisic BM, Filipovic-Danic Set al. Xanthine oxidase activity in type 2 diabetes mellitus patients with and without diabetic peripheral neuropathy. Journal Diabetes Research 2016; 2016, article 4370490:7.

8. Onuigbo NNJ, Unuigbe El, Oguijiofor. Dyslipidaemia in type 2 diabetes mellitus patient in Nnewi SOUTH-East Nigeria. Annals of African medicine 2011; 10(4):285-9.

9. Sushith, Shetty JK, Jappu AK et al. Lipid profile and atherogenic index of plasma (AIP) in diabetic nonsmoker and smoker in Costal Karnataka. IJ AJIMS 2012; 1(2):93-7.

10. Arshag D. Dyslipidemia in type 2 diabetes mellitus. Clinical Practice Endocrinology and Metabolsm 2009; 5:150-9.

11. Li Z, Huang Q, Sun L et al. Atherogenic Index in Type 2 Diabetes and its relationship with chronic microvascular complications. International Journal of Endocrinology 2018; Volume 2018, Article ID 1765835. 